\title{
Book Review of "The design of avalanche protection dams. Recent practical and theoretical developments"
}

\author{
V. Jomelli \\ CNRS, Meudon, France
}

THE DESIGN OF AVALANCHE PROTECTION DAMS. RECENT PRACTICAL AND THEORETICAL DEVELOPMENTS, EDITED BY: JÓHANNESSON, T., GAUER, P., ISSLER, P., AND LIED, K., CONTRIBUTIONS BY: BARBOLINI, M., DOMAAS, U., FAUG, T., GAUER, P., HÁKONARDÓTTIR, K. M., HARBITZ, C. B., ISSLER, D., JÓHANNESSON, T., LIED, K., NAAIM, M., NAAIMBOUVET, F., AND RAMMER, L., PUBLISHED BY: EUROPEAN COMMISSION DIRECTORATE-GENERAL FOR RESEARCH, 205 PAGES, ISBN 978-92-79-08885-8, ISSN 1018-5593, DOI:10.2777/12871, PUBLICATION EUR 23339, 2009.

Snow avalanche are a common type of mass movement in mountain areas worldwide. Avalanche protective measures have become increasingly important due to population growth and increasing tourism in many avalanche prone areas in the mountain areas.

This book provides a comprehensive picture of the design of dams and other protective measures in the run out zones of snow avalanches. Coordinated by T. Johannesson from Icelandic Meteorological office and 3 co-authors from the Norwegian Geotechnical Institute, it summarizes recent theoretical developments and the results of flied and laboratory studies from research projects supported by the European Commission.

A total of 12 scientists from different countries have contributed to this special volume composed of 16 chapters. The book starts with short recommendations to make easier consultations with local authorities and decision makers. Karstein Lied presents key points that have to be taken into account to facilitate the dialogue between avalanche experts and local authorities when avalanche dams are planned. Sections 3 and 4 give a rapid overview of methods used to design avalanche dams. The recent improvements in the understanding of the flow of snow avalanches against dams and other obstructions have been achieved by theoretical analyses

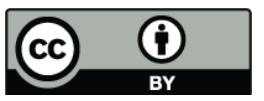

Correspondence to: V. Jomelli (vincent.jomelli@cnrs-bellevue.fr) experiments and numerical simulations enabling the formulation design criteria for catching and deflecting dams. Section 5 describes the dynamics of avalanche flow against obstructions and common aspects of the dam height criteria that apply to catching dams. A comparison of the proposed criteria with observations of natural avalanches that have hit dams or other obstacles underline the need for more observations of the run up of avalanches on man-made dams that can be used to validate the proposed dam height criteria.

Because the easiest way to control an avalanche is to guide it along a gently curving channel, special considerations for deflecting dams are given in Sect. 6. Aspects that are particular to either deflecting or catching dams such as the determination of the deflecting angle, or the curvature of the dam axis, and storage space above catching dams are treated through examples from Norway and Iceland. Results from chute experiments are proposed in order to determine the degree to which the run out of snow avalanches is reduced with such catching dams.

The nature of snow avalanches can be important in the design of avalanche dams. In Sects. 8 and 9 special considerations for wet snow avalanches are discussed because the flow from wet snow avalanches differs from the flow of drysnow avalanches in several ways such as internal cohesion, velocity, volume of snow for instance. General recommendations for the practical design of braking mounds are given because they are widely used for protection against dense wet snow avalanches. Section 10 discusses the effects of dams on powder snow avalanches. Special attention is given to the effects of dams on the suspension layer accompanying dense flow avalanches. Such aspect is justified by the fact that both deflecting and catching dams are usually built with the goal of preventing the dense part of avalanches from entering into vulnerable territory. However dry snow avalanches often form an accompanying suspension layer that may have a long run out distance and considerable destructive power. Recommendations for assessing the impact of power snow avalanches are proposed.

Published by Copernicus Publications on behalf of the European Geosciences Union. 
Sections 11-14 present design recommendations for dynamic loads from snow avalanches in the run out zones. Loads on walls on masts and narrow obstacles or loads due to impacts of solid bodies such as rock debris or trunks are considered.

Basic knowledge of the construction principles of retaining and deflecting dams is given in Sect. 15 in order to help the avalanche expert in the decision of dam planning. Finally guidelines dealing with unresolved issues are presented in Sect. 16.
As I said before this book summarizes the main results of two European projects combined with traditional design principles to form an important and welcomed improvement. A real effort has been made to make the read easy for authorities concerned with protection measures and risk management with practical aspects and numerous recommendations. For this reason, it represents a useful addition to the technical literature, and a good reading opportunity for scientists, engineers, and practitioners. 